
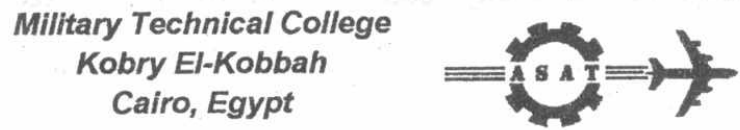

$10^{\text {th }}$ International Conference

On Aerospace Sciences\&

Aviation Technology

\title{
TECHNICAL JUSTIFICATION FOR USE OF NUMERICAL OR CONVENTIONAL MACHINES BASED ON SCORING SYSTEM
}

\author{
M.A.EL-HAKIM**, R.M.TAHER and M.A.EL-TAWAB
}

\begin{abstract}
The choice between numerical $(\mathrm{CNC})$ and conventional machines may be in many cases a hard task. In the present work a practical method is introduced to choose either CNC or conventional machines based on a scoring system that evaluates the technical aspects in each case. The system considers 15 factors that affect the decision-making and for each factor it is assigned a weighing value. These factors are grouped into 3 blocks describing the nature of the product, the nature of production and the existing facilities in the working place. Based on the final total score, a selection decision can be made. A case study is presented where the scoring system has been employed applied to it.
\end{abstract}

\section{Introduction}

One of the primary objectives in manufacturing engineering is to determine the most economical method for part production.

Among the major decisions encountered in process planning is the choice between numerical and conventional machine tools. It is not always obvious whether a particular part should be processed by one method or the other. In order to utilize the potential economic benefits of numerical control, only those parts that are appropriate for CNC must be processed on it $[1,2,3]$.

Currently there is no universally accepted procedure for deciding on parts to be processed by $\mathrm{CNC}$ machine tools. The decision is usually based on the experience of the process planner and the facilities available within the machine shop.

When the choice between CNC and conventional machine tools is not clear, alternative process plans or procedures must be developed.

The objective of the present study is to develop a scoring system and decision table for determining whether to process a part on CNC or conventional machines. In the use of this scoring system an analysis is made of the physical characteristics shown on the part print and of other known information about the part, such as lot size, number of batches per year...etc. these factors are assigned weighing values. The assigned values are then summed up and the selection decision is made $[4,5]$.

\footnotetext{
* Professor,Dept.of Production Engineering, Ain Shams Universit, Cairo,Egypt.

** Assosiate Professor,Dep.of Industrial Management and Engineering, Arab Academy for Science and Technolog, Alexandria, Egypt.

*** Research director, AIO, Cairo, Egypt.
} 
The proposed decision procedure would have the following potential benefits:

1- It is a straightforward procedure, which saves the time required for process planning

2- The procedure is independent on a particular process planner experience and judgement. It establishes a uniform decision making policy.

3- The user of the procedure, need not to have extensive background in manufacturing.

4- The decision is based on the most important factors, which should be considered in such a choice.

5- The procedure offers a satisfactory technical justification for deciding whether to buy $\mathrm{CNC}$ or conventional machine tools.

6- This procedure can easily be incorporated into a CAD/CAM system where the design and manufacturing plans for a part are completed with minimum human involvement.

\section{Developing the Scoring System.}

A scoring system is developed which considers 15 factors that would affect the decisionmaking for the selection between $\mathrm{CNC}$ and conventional machine tools.

These factors are grouped into 3 main blocks, which represent the nature of product, the nature of production and the existing facilities in the working place.

In order to use this scoring system, weighing values have to be assigned to each of the 15 factors. The assigned factor value depends on the particular work part and the relative importance of the factor. The most important factors are assigned values between 5 and 30 and the least important factors are assigned values between 3 and 8 .

The midpoint and the neutral values are chosen to indicate the breakeven between CNC and conventional machines. The weighing values are limited to integers for the sake of simplicity as shown in table (1).

After assigned weight values have been entered for all factors, these weights are summed up. The maximum value of the sum of weights is 145 and the minimum score is 45 , the average is taken to be 90 . A total score greater than 90 would tend to favor $\mathrm{CNC}$, while a score less than 90 would favor conventional machine tools. As the difference between the score and 90 becomes greater, this indicates a stronger tendency for the particular decision. A value of 90 would be inconclusive, presumably either method can be used.

The following will be a description of how to assign values for each of the 15 factors shown in table (4).

\section{Group (1) Nature of product}

\section{1- Degree of complexity.}

Complexity measures are introduced as shown in table (2) for turning operations as well as table (3) for milling and drilling operations. A higher complexity score favors the selection of CNC machine tools. Table (4.a) and (4.b) include the weighing points for the degree of complexity for both turning and milling and drilling operations respectively. 


\section{2- Accuracy.}

The assigned work piece accuracy can be classified into two types; form and dimensional accuracy. Each type is given 5 points. Table (6) shows the weighing points for form accuracy while table (7) shows the points for dimensional accuracy. The higher score favors the choice of $\mathrm{CNC}$ machines.

\section{3- Surface quality.}

Table (8) shows the weighing points for the surface quality factor. Generally CNC machines are capable of producing better surface finish.

\section{4- Part value.}

This factor is applicable to parts made of an expensive raw material or to parts with extensive previous processing. This process criterion is based on "YES" or "NO"

judgement. The extreme weighing points of 3 or 7 would be assigned to the cases of absolute "NO" or absolute "YES" judgement respectively, otherwise a value of 5 is assigned. Table (9) shows the scores of the part value. Higher scores need the processing to be with CNC machines.

\section{5- Engineering changes}

This is the number of engineering changes anticipated in the part design. Examples would be material and dimensional changes. This factor must be judged from previous similar parts. A part with frequent modifications in the drawing favors the use of $\mathrm{CNC}$ machine tools because of the easiness of modifying the program of machining the part than changing the fixture or a jig on a conventional machine tool.

This factor is assigned as shown in table (10).

\section{6- Lead time}

This is the time between placing an order by the customer and receiving the shipment. In general $\mathrm{CNC}$ machine tools reduce setting time, machining cycle time, inprocess inventory and inspection time. The lead time in some modern shops may be as short as two weeks. The assignment of weighing points to lead time is shown in table (11).

\section{7- Batch size}

Batch size means the number of parts in a lot. It is accepted that CNC is suitable for small and medium size lot sizes. If the lot size is extremely small it will not justify making a CNC program for the job. On the other hand, a large lot size ties down the CNC machine for a long period. The assumption used in assigning weighing factors to this criterion is based on the rule of thumb that "part lot size between 25 and 300 is appropriate for CNC processing". The assignment of the weighing points to lot size is shown in table (12).

\section{8- Recurrence of batches}

This is the number of times a particular part lot is repeated per year. A higher recurrence leads to a lower cost of planning, programming, less time for the first piece checkout etc. The weight values for the number of batches per year are given in table (13).

\section{9- Family of parts}

This is the classification of similar parts into a group such that a single set of solutions can be applied for processing any part within the group. Either a part falls into a group of similar parts or it does not, so that the process criterion is based on "NO" or "YES" judgement and only the extreme values of the weighing points ( 3 or 8 ) can be assigned respectively.

10- Quality control level

This factor refers to the level of inspection of the machined parts in a lot. A high inspection level usually applies to complicated parts which favors the selection of CNC machines. This factor is taken into consideration according to table (14). 


\section{Table (1) Decision Table between CNC and Conventional Machine Tools}

\begin{tabular}{|c|c|c|c|c|c|c|c|}
\hline Ser & $\begin{array}{l}\text { Main } \\
\text { Activity }\end{array}$ & \multicolumn{2}{|c|}{ Process Criteria } & \multirow{2}{*}{$\frac{\text { Points }}{25}$} & \multicolumn{3}{|c|}{ Scheme } \\
\hline \multirow{5}{*}{1} & \multirow{5}{*}{$\begin{array}{l}\text { Nature of } \\
\text { Product }\end{array}$} & 1 & Complexity & & 5 & 17 & 30 \\
\hline & & 2 & Accuracy & 10 & 1 & 6 & 11 \\
\hline & & 3 & Surface quality & 8 & 2 & 6 & 10 \\
\hline & & 4 & Part value & 4 & 3 & 5 & 7 \\
\hline & & 5 & $\begin{array}{l}\text { Engineering } \\
\text { changes }\end{array}$ & 3 & 4 & 5 & 7 \\
\hline \multirow{5}{*}{2} & \multirow{5}{*}{$\begin{array}{l}\text { Nature of } \\
\text { Production }\end{array}$} & 6 & Lead time & 5 & 3 & 5 & 8 \\
\hline & & 7 & Batch size & 5 & 3 & 5 & 8 \\
\hline & & 8 & Batches / year & 5 & 3 & 5 & 8 \\
\hline & & 9 & Family of parts & 5 & 3 & 5 & 8 \\
\hline & & 10 & Quality control & 5 & 3 & 5 & 8 \\
\hline \multirow{5}{*}{3} & \multirow{5}{*}{$\begin{array}{l}\text { Available } \\
\text { Working } \\
\text { Facilities }\end{array}$} & 11 & $\begin{array}{l}\text { Planning \& } \\
\text { Programming }\end{array}$ & 5 & 3 & 5 & 8 \\
\hline & & 12 & Skilled labor & 5 & 3 & 5 & 8 \\
\hline & & 13 & Tooling system & 5 & 3 & 5 & 8 \\
\hline & & 14 & Maintenance & 5 & 3 & 5 & 8 \\
\hline & & 15 & $\begin{array}{l}\text { Quality control } \\
\text { facilities }\end{array}$ & 5 & 3 & 5 & 8 \\
\hline \multicolumn{5}{|c|}{ Total score } & 45 & 90 & 145 \\
\hline \multicolumn{4}{|c|}{ Final Decision } & ventional & 4 & $\longrightarrow$ & $\mathrm{CNC}$ \\
\hline
\end{tabular}


Table (2) Degree of Complexity of the machined parts in turning operations

\begin{tabular}{|c|c|c|c|c|c|}
\hline Type & Ser & Operation & Score & $\begin{array}{c}\text { No. of } \\
\text { Surfaces }\end{array}$ & Total Score \\
\hline \multirow[t]{10}{*}{ External } & 1.1 & -Cylindrical Turning & 2 & & \\
\hline & 1.2 & -Facing & 2 & & \\
\hline & 1.3 & -Taper & 5 & & \\
\hline & 1.4 & -Contouring from straight & 20 & & \\
\hline & 1.5 & $\begin{array}{l}\text {-Contouring from inclined } \\
\text { line }\end{array}$ & 30 & & \\
\hline & 1.6 & -Contouring from contour & 50 & & \\
\hline & 1.7 & -Chamfering & 2 & & \\
\hline & 1.8 & -Under cutting & 2 & & \\
\hline & 1.9 & -Threading by die & 5 & & . \\
\hline & 1.10 & $\begin{array}{l}\text {-Threading by single point } \\
\text { tool }\end{array}$ & 10 & & \\
\hline \multirow[t]{15}{*}{ Internal } & 2.1 & -Cylindrical Turning & 4 & & \\
\hline & 2.2 & -Facing & 4 & & \\
\hline & 2.3 & -Taper & 10 & & \\
\hline & 2.4 & -Contouring from straight & 20 & & \\
\hline & 2.5 & $\begin{array}{l}\text {-Contouring from inclined } \\
\text { line }\end{array}$ & 40 & & 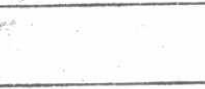 \\
\hline & 2.6 & -Contouring from contour & 60 & & \\
\hline & 2.7 & -Chamfering & 4 & & \\
\hline & 2.8 & -Under cutting & 8 & & \\
\hline & 2.9 & -Drilling & 4 & & \\
\hline & 2.10 & -Boring & 10 & & \\
\hline & 2.11 & -Deep Drilling & 10 & & \\
\hline & 2.12 & -Reaming & 10 & & \\
\hline & 2.13 & -Spotfacing & 10 & & \\
\hline & 2.14 & -Threading by tap & 10 & & \\
\hline & 2.15 & $\begin{array}{l}\text {-Threading by single point } \\
\text { tool }\end{array}$ & 20 & & \\
\hline
\end{tabular}


Table (3) Degree of Complexity of the machined parts in milling and drilling operations

\begin{tabular}{|c|c|c|c|c|c|}
\hline Ser & Operation & Score & $\begin{array}{c}\text { No. of } \\
\text { Surfaces }\end{array}$ & Total Score & Scheme \\
\hline $1-$ & $\begin{array}{l}\text {-Straight line parallel to } \\
\text { one of the axes }\end{array}$ & 2 & & & \\
\hline $2-$ & -Inclined straight line & 15 & & & \\
\hline $3-$ & $\begin{array}{l}\text {-Contouring from straight } \\
\text { line }\end{array}$ & 25 & & & \\
\hline $4-$ & $\begin{array}{l}\text {-Contouring from inclined } \\
\text { Straight line }\end{array}$ & 40 & & & \\
\hline 5- & -Contouring from contour & 60 & & & \\
\hline $6-$ & $\begin{array}{l}\text {-Drilling " } n \text { " holes on a } \\
\text { line }\end{array}$ & $2^{*} n$ & & & \\
\hline 7- & $\begin{array}{l}\text {-Deep drilling " } n \text { " holes } \\
\text { On a line }\end{array}$ & $4^{*} n$ & & & \\
\hline 8- & $\begin{array}{l}\text {-Boring " } n \text { " holes on a } \\
\text { line }\end{array}$ & $4^{*} n$ & & & \\
\hline 9- & $\begin{array}{l}\text {-Spotfacing " } n \text { " holes on } \\
\text { a line }\end{array}$ & $4^{*} n$ & & & \\
\hline 10 & $\begin{array}{l}\text {-Reaming " } n \text { " holes on a } \\
\text { line }\end{array}$ & $4^{*} n$ & & & \\
\hline $11-$ & $\begin{array}{l}\text {-Threading by tap " } n " \\
\text { holes on a line }\end{array}$ & $5^{*} n$ & & & \\
\hline $12-$ & $\begin{array}{l}\text { - Threading by a single } \\
\text { point tool " } n \text { " holes on } \\
\text { a line }\end{array}$ & $10^{*} n$ & & & \\
\hline $13-$ & $\begin{array}{l}\text {-Drilling " } n \text { " holes on a } \\
\text { circle }\end{array}$ & $5^{\star} n$ & & & \\
\hline $14-$ & $\begin{array}{l}\text {-Deep drilling " } n \text { " holes } \\
\text { On a circle }\end{array}$ & $10 * n$ & & & \\
\hline $15-$ & $\begin{array}{l}\text {-Boring " } n \text { " holes on a } \\
\text { circle }\end{array}$ & $10^{*} n$ & & & \\
\hline $16-$ & $\begin{array}{l}\text {-Spotfacing " } n \text { " holes on } \\
\text { a circle }\end{array}$ & $10^{*} n$ & & & \\
\hline $17-$ & $\begin{array}{l}\text { - Reaming " } n \text { " holes on } \\
\text { a circle }\end{array}$ & $10^{\star} n$ & & & \\
\hline $18-$ & $\begin{array}{l}\text {-Threading by tap " } n \text { " } \\
\text { holes on a circle }\end{array}$ & $10^{*} n$ & & & \\
\hline 19 & $\begin{array}{l}\text {-Threading by a single } \\
\text { point } \\
\text { tool "n" holes on a circle }\end{array}$ & $20 * n$ & & & \\
\hline
\end{tabular}


Table (4) Weighing points for the degree of complexity for turning operations

\begin{tabular}{|c|c|}
\hline Resulting Scores From Table (2) & Points \\
\hline$<=20$ & 5 \\
\hline$>20$ to 40 & 10 \\
\hline$>40$ to 80 & 15 \\
\hline$>80$ to 100 & 20 \\
\hline$>100$ & 30 \\
\hline
\end{tabular}

Table (5) Weighing points for the degree of complexity for drilling and milling operations

\begin{tabular}{|c|c|}
\hline Resulting Scores From Table (3) & Points \\
\hline$<=50$ & 5 \\
\hline$>50$ to 100 & 10 \\
\hline$>100$ to 200 & 15 \\
\hline$>200$ to 400 & 20 \\
\hline$>400$ & 30 \\
\hline
\end{tabular}

Table (6) Weighing factors for form accuracy

\begin{tabular}{|c|c|}
\hline Level of form accuracy & Points \\
\hline Low (not specified) $(\mathrm{L})$ & 1 \\
\hline Medium $>0.01 \quad(\mathrm{M})$ & 3 \\
\hline High $<=0.01 \quad(\mathrm{H})$ & 6 \\
\hline
\end{tabular}

Table (7) Weighing factors for dimensional accuracy

\begin{tabular}{|c|c|c|}
\hline $\begin{array}{c}\text { Tolerance Level } \\
(\mathrm{LT} \mathrm{mm})\end{array}$ & $\begin{array}{c}\text { Number } \\
\text { of dimensions }\end{array}$ & Points \\
\hline $\mathrm{LT}>=0.1$ & $\mathrm{NLT}=<4$ & 1 \\
\hline $\mathrm{LT}>=0.1$ & $\mathrm{NLT}>4$ & 2 \\
\hline $0.01<\mathrm{LT}<0.1$ & $\mathrm{NLT}<4$ & 3 \\
\hline $0.01<\mathrm{LT}<0.1$ & $\mathrm{NLT}>=4$ & 4 \\
\hline $\mathrm{LT}=<0.01$ & $\mathrm{NLT}>=1$ & 6 \\
\hline
\end{tabular}


Table (8) Surface Roughness Score Values

\begin{tabular}{|c|c|c|}
\hline $\begin{array}{c}\text { Surface Roughness } \\
R_{a} \text { (um) }\end{array}$ & No. of surfaces & Points \\
\hline$R_{a}>=3.2$ & All & 2 \\
\hline $1.6<R_{a}<3.2$ & $=<2$ & 3 \\
\hline $1.6<R_{a}<3.2$ & $>2$ & 4 \\
\hline $0.8<R_{a}<1.6$ & $=<2$ & 5 \\
\hline $0.8<R_{a}<1.6$ & $>2$ & 6 \\
\hline$R_{a}=<0.8$ & $=<2$ & 8 \\
\hline$R_{a}=<0.8$ & $>2$ & 10 \\
\hline
\end{tabular}

Table (9) Part Value Scores

\begin{tabular}{|c|c|c|c|c|}
\hline Condition of the part & \multicolumn{4}{|c|}{ Judgement } \\
\hline Expensive material & Yes & Yes & No & No \\
\hline $\begin{array}{c}\text { Part with extensive previous } \\
\text { machining }\end{array}$ & Yes & No & Yes & No \\
\hline Total points & & & & \\
\hline
\end{tabular}

Table (10) Weighing points for engineering changes

\begin{tabular}{|c|c|}
\hline Number of anticipated changes & Points \\
\hline Very few or no changes $(=<1)$ & 3 \\
\hline Few to average changes $(>=2$ to 6$)$ & 5 \\
\hline Frequent changes [Prototypes] $(=>6)$ & 7 \\
\hline
\end{tabular}

Table (11) Weighing points for lead time

\begin{tabular}{|c|c|}
\hline \multicolumn{1}{|c|}{ (LDT months) } & Points \\
\hline LDT $>=9$ & 3 \\
\hline $4=<$ LED $<9$ & 4 \\
\hline $2=<$ LDT $<4$ & 5 \\
\hline $0.5=<$ LDT $<2$ & 6 \\
\hline LDT $<0.5$ & 8 \\
\hline
\end{tabular}


Table (12) Weighing points for batch size

\begin{tabular}{|c|c|}
\hline Lot size & Points \\
\hline $\mathrm{BSZ}<5$ or $\mathrm{BSZ}>300$ & 3 \\
\hline $5=<\mathrm{BSZ}<15$ or $270<\mathrm{BSZ}=<300$ & 4 \\
\hline $15=<\mathrm{BSZ}<30$ or $200<\mathrm{BSZ}=<270$ & 5 \\
\hline $30=<\mathrm{BSZ}<100$ & 6 \\
\hline $100<\mathrm{BSZ}=<200$ & 8 \\
\hline
\end{tabular}

Table (13) Weighing points for the number of batches per year

\begin{tabular}{|c|c|}
\hline Batches per year & (BBY) \\
\hline BPY $=<1$ & 3 \\
\hline $1<\mathrm{BPY}=<3$ & 4 \\
\hline $3<\mathrm{BPY}=<5$ & 5 \\
\hline $5<\mathrm{BPY}=<8$ & 6 \\
\hline $\mathrm{BPY}>8$ & 8 \\
\hline
\end{tabular}

Table (14) Weighing points for the work piece inspection \%

\begin{tabular}{|c|c|}
\hline Inspection $\%$ (insp) & Points \\
\hline Insp \%=<30\% & 3 \\
\hline $30 \%<\operatorname{lnsp} \%=<70 \%$ & 5 \\
\hline $\operatorname{Insp} \%>70 \%$ & 8 \\
\hline
\end{tabular}




\section{Group (3). Available working facilities}

This factor takes into consideration the available engineering facilities, such as planning and programming skilled labor, tooling, maintenance, inspection, and quality control level. The decision of buying a CNC machine tool is justified if the factory possesses modern engineering facilities with a high technical level such as:

\section{1- Planning and programming facility}

The existence of an experienced planning and programming section in the factory favors the decision of buying a CNC machine tool, but if the factory does not have this capability, such a decision may not be preferred. In these conditions conventional machine tools may be preferred.

\section{2- Skilled labor}

The availability of skilled labor justifies the processing of complicated machined components on conventional machine tools, while scarcity of skilled labor favors the use of CNC machine tools.

\section{3- Tooling facility}

That is the availability of a well organized system of jigs, fixtures and tool design and manufacturing which favors the use of conventional machine tools, while poor tooling facility favors the use of CNC machine tools.

\section{4-Maintenance facility}

Which includes mechanical, electrical and electronic maintenance capability. A high maintenance capability favors the choice of CNC machine tools, while a poor maintenance capability favors the choice of conventional machine tools.

\section{5-Inspection facility}

The existing quality control level in the factory affects the decision of selecting the suitable machine tool; a high quality control level favors the choice of a conventional machine tool, while a lower quality control level favors the choice of CNC machine tool because of the lower reject it produces and the lower inspection effort needed.

Table (15) includes the suggested weighing factors for the workplace available facilities.

Table (15) Weighing points for the work place facilities

\begin{tabular}{|l|c|c|c|}
\hline \multicolumn{1}{|c|}{ Work place facilities } & L.ow & Medium & High \\
\hline Planning and programming & 3 & 5 & 8 \\
\hline Skilled labor & 8 & 5 & 3 \\
\hline Tooling & 8 & 5 & 3 \\
\hline Maintenance & 3 & 5 & 8 \\
\hline Inspection & 8 & 5 & 3 \\
\hline
\end{tabular}




\section{Case Study}

As a practical application of the theoretical study carried out in the present work, a case study in milling has been selected to demonstrate how the developed scoring system works. The presented case is of a cover plate fig (1) made of $6061 \mathrm{~T} 6 \mathrm{Al} \mathrm{Si} \mathrm{Mg}$ alloy with dimensions $350 \times 150 \times 4 \mathrm{~mm}$, hardened to BHN 90 and has a tensile strength of $270 \mathrm{M} \mathrm{Pa}$.

It has been suggested to finish the given work piece by slot milling one part at a time in a single pass peripheral milling using:

- End mill $\phi 6 \mathrm{~mm}, 4$ teeth

- Two flutes slot drill $\phi 6 \mathrm{~mm}$

Selected values of the feed per tooth $>0.01 \mathrm{~mm}$ has led to the breakage of the end mill. The slot drill with feed per tooth of $0.02 \mathrm{~mm}$ has been used successfully since it avoids the causes of failure of the end mill. The machining of the part was carried out on a $\mathrm{CNC}$ vertical milling machine with automatic tool changer and a tool drum of 6 tools capacity. The sequence of machining steps of the given part starts with contour milling with a slot drill $\phi 6 \mathrm{~mm}$, then drilling the shown 8 holes with a drill $\phi 6.6 \mathrm{~mm}$ and ending with tapping these holes with taps M8 x $1.25 \mathrm{~mm}$.

\section{$\underline{\text { Results and Discussions }}$}

Only the evaluation of degree of complexity of the machined part will be demonstrated here since it is most critical and also the most complicated factor to be evaluated. Table ( 16 ) shows the scores obtained for individual items in this table and also the total score which equals 161. Referring to table (5), this total score corresponds to 15 points. These 15 points are plugged in table ( 17 ) which is the final decision table. The other factors were calculated by collecting the proper information from the factory, which produces the given part, and by the use of tables in the developed system. The final total score in the decision table was 104, which suggests the use of CNC machine to process the given part.

\section{Conclusions}

In cases when economical justification for use of $\mathrm{CNC}$ machines is not possible (or not clear) or when technical justification is required to complement the economic one, the developed scoring system would be a good alternative for decision making based on the technical aspects of the produced parts. The application of the proposed scoring system to the presented case study has proved the associated potential benefits of the system previoisly stated in the theoretical part of this work 


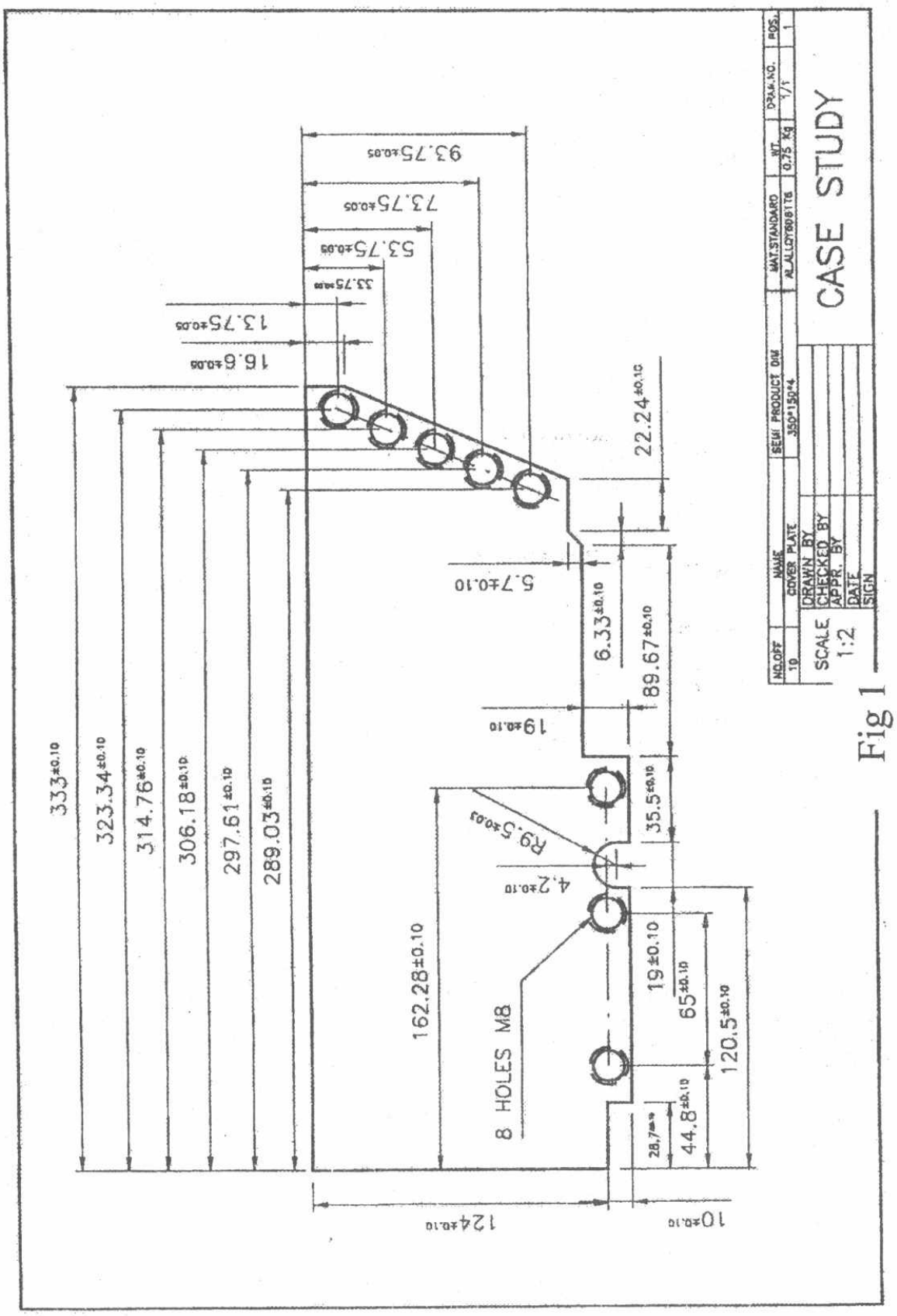


Table (16) Degree of complexity of the machined part

\begin{tabular}{|c|c|c|c|c|c|}
\hline Ser & Operation & Score & $\begin{array}{c}\text { No. of } \\
\text { Surfaces }\end{array}$ & Total Score & Scheme \\
\hline 1 & $\begin{array}{l}\text { Straight line parallel to } \\
\text { one of the axes }\end{array}$ & 2 & 5 & 10 & \\
\hline 2 & Inclined straight line & 15 & 2 & 30 & \\
\hline 3 & Contouring from straight line & 25 & 1 & 25 & \\
\hline 4 & $\begin{array}{l}\text { Contouring from inclined } \\
\text { straight line }\end{array}$ & 40 & 1 & 40 & \\
\hline 5 & Contouring from contour & 60 & - & - & \\
\hline 6 & Drilling " $n$ " holes on a line & $2 * n$ & 8 & 16 & \\
\hline 7 & $\begin{array}{l}\text { Deep drilling " } n \text { " holes on } \\
\text { a line }\end{array}$ & $4^{*} n$ & - & - & \\
\hline 8 & Boring " $n$ " holes on a line & $4^{*} n$ & - & - & \\
\hline 9 & $\begin{array}{l}\text { Spotfacing " } n \text { " holes on } \\
\text { a line }\end{array}$ & $4^{*} n$ & - & - & \\
\hline 10 & Reaming " $n$ " holes on a line & $4^{*} n$ & - & - & : \\
\hline 11 & $\begin{array}{l}\text { Threading by tap " } n \text { " holes } \\
\text { on a line }\end{array}$ & $5^{*} n$ & 8 & 40 & \\
\hline 12 & $\begin{array}{l}\text { Threading by a single point } \\
\text { tool " } n \text { " holes on a line }\end{array}$ & $10^{*} n$ & - & - & \\
\hline 13 & Drilling " $n$ " holes on a circle & $5 * n$ & - & - & \\
\hline 14 & $\begin{array}{l}\text { Deep drilling " } n \text { " holes on } \\
\text { a circle }\end{array}$ & $10^{*} n$ & - & - & \\
\hline 15 & Boring "n" holes on a circle & $10^{*} \mathrm{n}$ & - & - & \\
\hline 16 & $\begin{array}{l}\text { Spotfacing " } n \text { " holes on } \\
\text { a circle }\end{array}$ & $10^{*} n$ & - & - & \\
\hline 17 & $\begin{array}{l}\text { Reaming " } n \text { " holes on } \\
\text { a circle }\end{array}$ & $10^{*} n$ & - & - & \\
\hline 18 & $\begin{array}{l}\text { Threading by tap " } n \text { " holes } \\
\text { on a circle }\end{array}$ & $10^{*} n$ & - & - & \\
\hline 19 & $\begin{array}{l}\text { Threading by a single point } \\
\text { tool " } n \text { " holes on a circle }\end{array}$ & $20^{*} n$ & - & - & \\
\hline 20 & Chamfer of holes & $5 * n$ & - & - & \\
\hline \multicolumn{4}{|c|}{ Total score } & 161 & \\
\hline
\end{tabular}


(Table 17) Decision table between CNC and Conventional Machine Tools

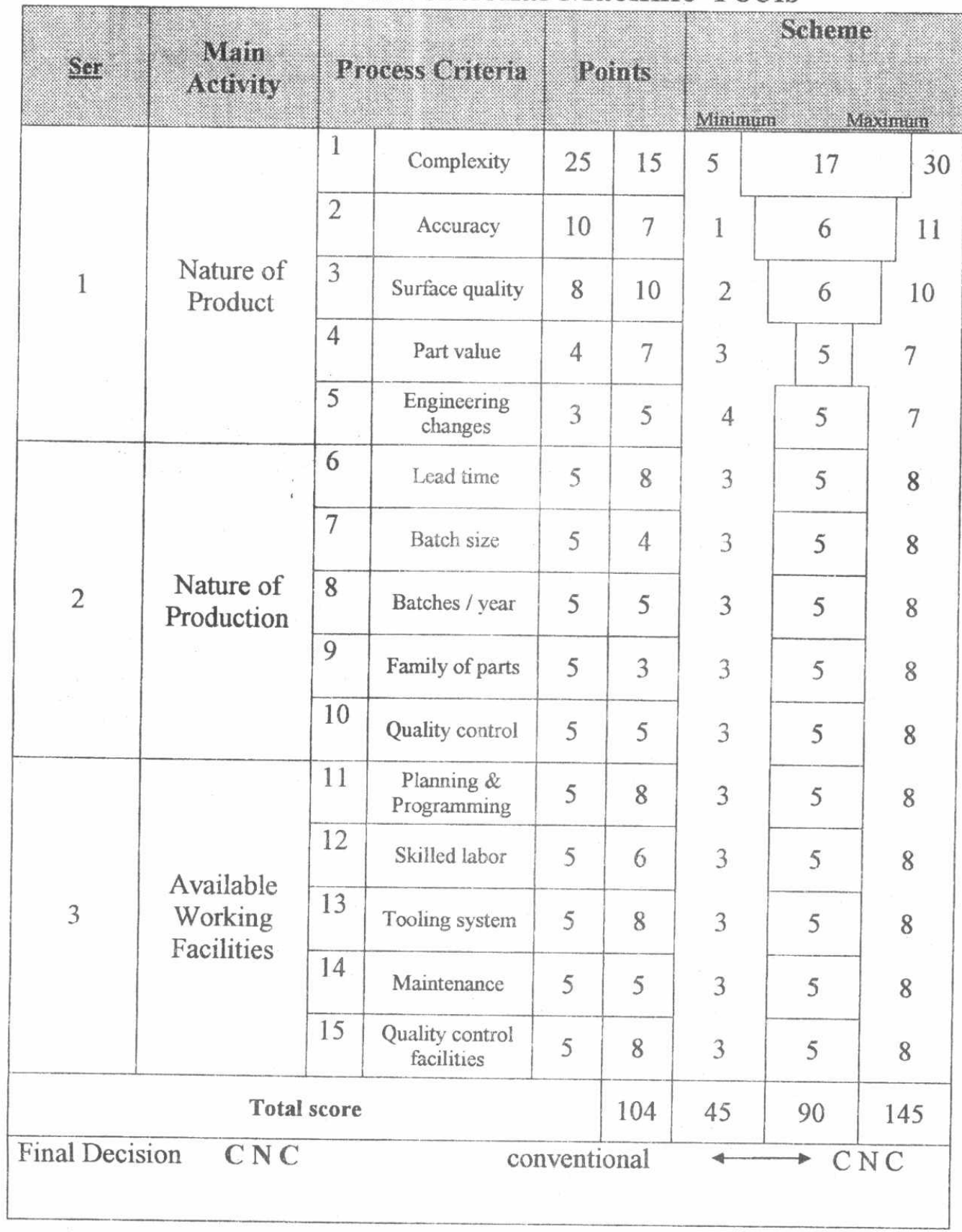




\section{References}

1. Groover, M.P, Automation, Production Systems and Computer Aided Manufacturing, Prentice-Hall, Inc. Englewood Cliffs, New Jersey, 1980

2. Tawab, M. A., "An Investigation into the Optimum Selection of Machine Tools by the Aid of Computers", M.Sc. Thesis, Faculty of Engineering, Ain Shams University, 1992.

3. "Justifying Computers in Manufacturing Hidden Savings Brought to Light", American Mechanist, Computers in Manufacturing, 1983, pp.165 - 174.

4. Opitz, H., H.P. Wiendahl, " Group Technology and Manufacturing Systems for Small Quantity Production, Int. J. Prod. Res., Vol. 9, no.1, pp.181, 1971

5. Debar, A.E., "Automatically Controlled Machine Tools", Chartered Mech. Eng., Vol. 20, no. 1, pp. 81, January 1973 